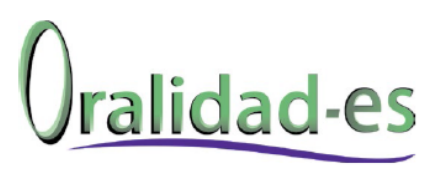

\title{
Oralidad artística: arte performativa y 'desocultamiento del Ser' en la era de la postmodernidad
}

\author{
Artistic orality: performative art and 'uncovering of the Being' \\ in the postmodern era
}

Luciana Benítez-Schaefer benitez_schaefer@hotmail.com

Universidad Nacional de Cuyo, Argentina

Benítez-Schaefer, L. (2019). Oralidad artística: arte performativa y 'desocultamiento del Ser' en la era de la postmodernidad. Oralidad-es, 5, 1-10. https://revistaoralidad-es.com/index.php/ro-es/article/view/113

Fecha de recepción: 24 de septiembre de 2019 / Fecha de aprobación: 13 de octubre de 2019 


\section{Resumen}

El presente trabajo pretende explicar la vigencia e importancia de las prácticas orales artísticas a partir de la conceptualización de la performance oral como síntesis de dos elementos opuestos, pero complementarios: la evanescencia propia del habla y la necesidad ontológica de la "verdad" (en el sentido fenomenológico del término). Esta búsqueda remite al concepto de "universalidad" en una era postmoderna, donde ambas nociones tienden a ser cuestionadas. Desde una perspectiva dinámica del lenguaje como juego (L. Wittgenstein) y de la comunicación como proceso que incluye elementos verbales y no verbales (Teoría de Sistemas Dinámicos, desde los estudios de P. Reygadas y S. Shanker), la autora brinda un sustento teórico a la vitalidad de este arte ancestral en la época actual. Así, esta investigación promueve la práctica de la oralidad como recurso para asimilar y comprender el universo cultural que nos precede y nos rodea.

\section{Palabras clave}

Postmodernidad; fenomenología; performance; oralidad secundaria; sprachspiel (juego del lenguaje)

\section{Abstract}

The present work attempts to explain the validity and importance of oral artistic practices from the conceptualization of oral performance as a synthesis of two opposite but complementary elements: the evanescence of speech and the ontological need for "truth" (in the phenomenological sense of the term). This search refers to the concept of "universality" in a postmodern era, where both notions tend to be questioned. From a dynamic perspective of language as a game ( $\mathrm{L}$. Wittgenstein) and of communication as a process that includes verbal and nonverbal elements (Theory of Dynamic Systems according to P. Reygadas and S. Shanker), the author provides theoretical support to the vitality of this ancestral art in current times. This research promotes the practice of orality as a resource to assimilate and understand the cultural universe that precedes and surrounds us.

Key words:

Postmodernity; phenomenology; performance; secondary orality; sprachspiel 
El presente trabajo pretende explicar la vigencia e importancia de las prácticas orales artísticas. Para ello, inicialmente se considera la concepción fenomenológica del arte como recurso para acceder a la verdad, desarrollada en un comienzo por Georg Wilhelm Friedrich Hegel y posteriormente por Martin Heidegger y Hans-Georg Gadamer.

Teniendo en cuenta dichas reflexiones, y atendiendo a la dimensión artística de la oralización de textos, se aborda la particular condición de lo que el semiólogo André Helbo denomina "artes del espectáculo vivo” y la noción de performance que ofrece Paul Zumthor, quien estudia la transmisión oral de mensajes poéticos.

Los insumos previamente enunciados son analizados en función de la noción de lenguaje como juego, propuesta por Ludwig Wittgenstein y retomada por la actual Teoría de Sistemas Dinámicos (en los aportes de Pedro Reygadas Robles-Gil y Stuart Shanker), para brindar al lector una visión de las prácticas orales como síntesis de dos elementos opuestos, pero complementarios: la evanescencia propia del habla y la necesidad ontológica de la "verdad" (en el sentido fenomenológico del término), búsqueda que remite al concepto de "universalidad" en una era postmoderna, donde ambos conceptos tienden a ser cuestionados.

De este modo, el trabajo brinda el sustento teórico que permite explicar el evidente sostenimiento de este arte ancestral en la época actual y promueve la práctica de la oralidad como recurso para asimilar y comprender el universo cultural que nos precede y rodea.

\section{Concepción fenomenológica del arte como modo de acceder a la "verdad"}

\author{
El siglo XX estuvo marcado por dos hechos
}

históricos que derrumbaron los pilares de la modernidad: las guerras mundiales. En un mundo devastado por la muerte, el hambre y la incertidumbre, dos filósofos -Martin Heidegger en Arte y Poesía (1952) y Hans-Georg Gadamer en Verdad y Método (1960)-, reflexionan en torno del arte como saber.

Esta elección hunde sus raíces en necesidades ontológicas vinculadas con la definición de "lo humano" y el rol que el arte y la palabra desempeñan en relación con dicho concepto, vulnerado a raíz de las convulsionadas circunstancias en que vivieron sus autores.

¿Qué es el arte? ¿Dónde se halla la "verdad”? ¿En qué medida puede ayudar lo artístico a que el sujeto acceda a ella? ¿En qué grado el arte -en este trabajo entendida especialmente como el uso artístico de la palabra oral- define al "ser", lo transforma y configura a lo largo de su existencia, en tanto experiencia? ¿Es el arte un aspecto insoslayable de lo humano?

¿Qué mecanismos y trampas sutiles existen para nublar una vivencia estética y cuáles son las consecuencias que esto podría generar o ha, en efecto, provocado en los siglos XX y XXI?

Si bien, como se ha comentado, las preguntas anteriormente expuestas pueden comprenderse en el marco histórico de una humanidad autocuestionada, devastada por la guerra, sus respuestas trascienden el contexto de producción y continúan promoviendo actualmente nuevas reflexiones, motivadas y enriquecidas, a su vez, a

\footnotetext{
${ }^{1}$ Conviene reflexionar sobre las dos acepciones que posee la palabra "verdad": aquella que nos otorga la ciencia positivista, alcanzada por medio de un método, y la planteada por la Fenomenología, que implica un autoconocimiento, un desocultamiento dinámico permanente, consistente en el reconocimiento progresivo de la verdad de aquello que cada uno es o está siendo a cada momento. Para Heidegger, resulta necesario colocar dentro del concepto de "verdad" lo bello y la experiencia artística, que desborda la acepción validada por la ciencia positivista.
} 
partir de otras revoluciones (lingüísticas, sociales, políticas, tecnológicas) que redefinen los conceptos de "lenguaje", "arte" y "humanidad".

Las palabras de Heidegger, publicadas en Arte $y$ poesía, resuenan hoy con el mismo vigor que cuando fueron escritas, alertando al lector de la importancia que el arte posee en tanto elemento fundamental y fundacional de la identidad de los pueblos: "Siempre que el arte acontece, es decir, cuando hay un comienzo, se produce en la historia un empuje y esta comienza o recomienza" (Heidegger, 1958, p. 117). Por ello, el autor, se refiere al origen de la obra de arte como el nacimiento simultáneo "de los creadores y de los contempladores, es decir, de la existencia histórica de un pueblo" (Heidegger, 1958, p. 118).

Para este filósofo, el arte implica un salto, un vuelo, un constante desafío de las normas, una lucha entre lo establecido y lo posible. La auténtica obra de arte se nos revela, en palabras de Heidegger, como una manifestación extraordinaria e innovadora, capaz de revertir el curso de la Historia o incluso de "comenzarla", si se tiene en cuenta que se proyecta al futuro para desocultar, develar aquello que un pueblo es, pero aún ignora.

La reflexión sobre esta lucha otorga a quien contempla las herramientas para cuestionar su propia concepción de "arte" y le brinda la posibilidad de elegir la importancia que le otorgará a las manifestaciones artísticas: si las tomará como un posible camino hacia la verdad (entendida como un desocultamiento del ser), como un mero entretenimiento o como un instrumento para concretar fines económicos, políticos o de otra índole no vinculados con su función genuina.

La concepción de "arte" de este filósofo sirve especialmente al propósito de este trabajo, ya que, para este pensador, el valor de la obra de arte no radica únicamente en la obra o en su autor, sino, principalmente, en aquel que la contempla, en el espectador. Esta convicción fenomenológica generó poco después, gracias a la labor de Hans-Georg Gadamer, lo que en el ámbito de las Letras se conoce como "Teoría de la recepción"2, perspectiva que repara en el lector/espectador como elemento constitutivo del hecho artístico activo (ya no un mero receptor de contenidos). Desde esta perspectiva, el destinatario es capaz de aportar sentido a la obra a partir de su interpretación, actualizándola en su tiempo, en su espacio y según su propia experiencia previa, completando la obra de arte, que no tendría sentido si careciera de alguien que la contemple.

Pocos años después de la primera edición de Arte y poesía, este segundo filósofo escribe Verdad y Método (1960), que refuerza la visión del arte como un aspecto constitutivo de la existencia humana y se enfoca en considerarla un recurso para alcanzar el autoconocimiento ("verdad"). Dicha revelación, según el autor, se produce a través de la comprensión de la obra de arte, que opera en quien la contempla hasta transformarlo. La obra revela, aspectos del observador que este no conocía, pero que se encuentran reflejados en la obra, como en un espejo. Se produce entonces una retroalimentación dinámica a partir de la experiencia o vivencia artística: quien contempla otorga sentido a la obra y la obra acrecienta y enriquece el interior de quien la contempla.

Gadamer repara en las transformaciones que el arte opera en el espectador; reivindica, como Heidegger, la posibilidad que brinda la experiencia artística de alcanzar una auto-comprensión y superar la vivencia puntual para permitir en el destinatario una transformación profunda a partir del vínculo establecido con la obra de arte, relación que afectará el ser de quien contempla más allá de la experiencia puntual en que dicha fusión se produjo.

\footnotetext{
${ }^{2}$ Los exponentes de esta teoría, Hans Robert Jauss y Wolfgang Iser, sustentan sus investigaciones en los trabajos de Gadamer, influido a su vez por las reflexiones filosóficas de Heidegger, su amigo y maestro.
} 
$\mathrm{Al}$ romper con la visión de arte únicamente como objeto factible de ser justipreciado (concepción validada por la Estética), Gadamer afirma la existencia de un conocimiento al que la obra nos permite acceder. Sin embargo, el camino para llegar a este conocimiento (que no es sino el conocimiento de uno mismo) se diferencia del propuesto por la ciencia positivista, que había llevado a la humanidad de su tiempo a la apoteosis de la tecnología y a las trágicas consecuencias de dicha ponderación. En el intento por reivindicar el arte como aspecto fundamental del ser humano y la necesidad de no soslayarla como un mero adorno de la cultura, tanto Heidegger como Gadamer alertan sobre los peligros de considerar como verdad los cánones estéticos. Estos imponen cierta visión sobre las producciones artísticas. Estas modas tienden a desviar el eje hacia lo que debe ser considerado bello, analizan elementos constitutivos de la obra, pero no se detienen a contemplar la obra de arte como una fuente, capaz de brindar claves para la autocomprensión en la contemplación del hecho artístico.

Heidegger reflexiona sobre la estética y la crítica de arte en tanto "consideración propia sobre al arte y el artista” (Heidegger, 1958, p. 120). La estética, "toma a la obra de arte como un objeto" (Heidegger, 1958, p. 120), capaz de ser percibido sensiblemente (en un amplio sentido de la palabra). Él no se halla conforme con este modo de concebir el arte. El salto que plantea se vincula con la idea de vivencia, y es dicho salto el que retoma Gadamer, cuando afirma:

Todo encuentro con el lenguaje del arte es encuentro con un acontecer inconcluso y es a la vez parte de este acontecer. A esto es a lo que se trata de dar vigencia frente a la conciencia estética y su neutralización del problema de la verdad (Gadamer, 1960, p. 141).
En este sentido, cabe preguntarse, con el filósofo, por la condición contradictoria de la tarea de la Estética como disciplina: “¿No estriba justamente la tarea de la estética en ofrecer una fundamentación para el hecho de que la experiencia del arte es una forma especial de conocimiento? (Gadamer, 1960, p. 139).

Esta conclusión fenomenológica, relacionada en última instancia con el modo que tenían los Antiguos de vincularse con el mundo (es decir, observando y analizando aquello que está y no creando un método apriorístico para su análisis), aún compite con otras concepciones del arte que atentan contra esta visión y que cuentan con una larga tradición ${ }^{3}$.

De este modo, lo que podría inicialmente aparecer ante el lector como un mero ejercicio retórico que tiene poco que ver con la realidad que lo rodea, se constituye en el centro del fundamento que el arte posee para la condición humana: no reconocer el arte como modo de llegar a la verdad (entendida como autoconocimiento), considerarla una mera fantasía producto del ingenio, ha generado graves consecuencias tales como la mecanización del hombre y su progresiva alienación.

Así, dado que según el positivismo todo lo verdadero puede ser (pre)dicho desde el método científico, resulta factible concebir una tendencia futura a la homogeneización del pensamiento y la progresiva masificación del hombre por medio de la anulación o menosprecio de la creatividad y el arte como aspecto fundamental de lo humano ${ }^{4}$.

Si, como promueven las distintas corrientes de la Estética, las producciones artísticas deben ser analizadas a partir de los cánones que determinan cómo debe crear el artista para ser conocido y aceptado socialmente y cómo debe leerse el

\footnotetext{
${ }^{3}$ Entre ellas, se encuentra la actual tendencia de los críticos a cuestionar la jerarquía del canon clásico frente a otros, creados ad hoc con distintos fines.

${ }^{4}$ Puede considerarse parte de este proceso el fenómeno de los best sellers y la mercantilización de la Literatura, junto con la masificación promovida en la formación del criterio estético de los lectores, por parte de las corporaciones editoriales.
} 
arte para sentirse parte de un colectivo social, entonces jen qué momento se ha perdido la conexión con aquello que permite al autor y al espectador decirse a si mismos en la obra? ¿existe la posibilidad de tal conexión si el "modo" de elaborar, observar y analizar dicha creación artística ha sido manipulado con diversos fines?

Las reflexiones hasta aquí expuestas resultan necesarias porque permiten preparar un espacio para la obra de arte (al evidenciar su importancia óntica, histórica y social), por que abren al creador su camino (en tanto que le devuelven el valor de su hacer y su sentido de existir) y otorgan al contemplador su lugar (no como alguien que meramente se entretiene con el arte, sino como un verdadero re-pensador de su propia existencia).

Así, el arte se abre camino constantemente frente a las adversidades que le tocan. Abreva en los géneros antiguos y los adapta a contextos aparentemente hostiles. Se recrea a sí misma para continuar siendo un modo de llegar a la anhelada verdad (saber que implica una comprensión de aquello contemplado, una transformación profunda de quien contempla a partir de la incorporación de aquello que se contempla).

El arte, más allá de los cánones que seguirán pretendiendo asirla a manifiestos estéticos o ideológicos y reglamentos, y más allá aún de las modas, se abre camino como un medio, un modo de llegar a conocer aquello que somos, tanto individual como colectivamente, vinculándose con un conocimiento, por el solo hecho de hallarse allí como creación contemplada. Así, el arte como parte de la existencia humana permite que sus producciones y los encuentros con estas sean puertas (universales) siempre abiertas a nuevas reflexiones y vivencias artísticas, a nuevas experiencias de contemplación que irán develando lo que estamos siendo a cada paso.
Lo dicho hasta aquí sobre el arte en general, puede ser aplicado a las prácticas orales artísticas, que hoy parten de una noción de "lenguaje" dinámica y compleja, como se observa a continuación.

\section{Dinamismo y complejidad en la Performance oral como "arte del espectáculo vivo"}

Las reflexiones de Ludwig Wittgenstein en sus Investigaciones filosóficas (escritas entre $1945 \mathrm{y}$ 1949 , y publicadas luego de su muerte, en 1953) quiebran la concepción de "lenguaje" como sistema ideal y estático, para dar paso a una definición más vinculada con una construcción en permanente transformación. Para este autor, el lenguaje es una "forma de vida", un "juego", cuyas cambiantes reglas se conocen a través de la observación y el uso.

Para Wittgenstein, el lenguaje, que permite la comunicación, genera en quienes lo utilizan cotidianamente una figura del mundo. Este modo de concebirlo como un hacer cotidiano en permanente cambio y actualización, es retomado y complementado por Pedro Reygadas y Stuart Shanker en su libro El rizoma de la racionalidad: el sustrato emocional del lenguaje (2007). Estos autores ponen de relieve el valor de las comunicaciones orales y reflexionan sobre los elementos no verbales que intervienen en el proceso de comunicación oral, a diferencia de lo que ocurre con el uso de la escritura. Estos elementos están constituidos por: entonación y aspectos no verbales de la palabra; miradas y contacto visual; expresiones faciales, gestos; posturas y orientación de ellas; relaciones de proximidad y distancia; contacto físico; apariencia; sentido del tiempo ('cronímica'); inclinaciones y movimientos de cabeza (Reygadas y Shanker, 2007, p. 12). 
La labor del narrador oral abreva en estos recursos para la realización de su tarea, pero suma la dificultad de un uso artístico de la palabra y del recurso no verbal, con lo que dinamismo y complejidad se potencian: El uso convencional es desafiado por "juegos del lenguaje" extraordinarios, que ponen a prueba la interpretación del espectador, en la orquestación de sentido que realiza junto con el narrador.

El fenómeno fue ampliamente estudiado por Paul Zumthor en Introducción a la poesía oral (publicado en 1983), quien repara en el sentido anglosajón de "performance", término definido por él como "[...] la acción compleja por la que un mensaje poético es simultáneamente transmitido y percibido, aquí y ahora (Zumthor, 1991, p. 33).

Este medievalista reflexiona especialmente sobre la "corporalidad", la "sensorialidad" que poseen los textos tradicionales ${ }^{5}$, concebidos como "objetos de percepción sensorial” (Zumthor, 2006, p. 12), factibles de ser cantados, recitados, representados, con todo lo que ello implica: cierta vestimenta, la ejecución de instrumentos, el uso de determinados espacios, la recepción colectiva de los mismos, etc.).

La realización de una performance implica, así, la interacción de distintos elementos o factores verbales y no verbales, cuyo tratamiento también resulta particular, dada su planificación previa. El medievalista suizo se refiere a ellos de la siguiente manera: "[...] [el] aliento, el sonido, el gesto, la instrumentación o el decorado [...] palabras y frases, sonoridades, ritmos, elementos visuales" (Zumthor, 2006, p. 41).

A lo largo de los siglos, dicha interacción entre elementos verbales y no verbales ha sido sostenida por Aedos, scopas, juglares, griots y otros perfor- mers, quienes, adaptándose a las convenciones de su época y sus lugares de origen, han llevado al extremo el dinamismo dialógico de una comunicación "en vivo", original y evanescente. De ello quedan, en ocasiones, rudimentarios vestigios fijados total o parcialmente por la escritura.

La condición efímera de las prácticas orales aludida complejiza su descripción, análisis y catalogación. En un intento por establecer pautas que diferencian las artes del espectáculo performativas, de otras manifestaciones artísticas, el semiólogo del teatro André Helbo profundiza la noción de "artes del espectáculo vivo", en su libro El teatro: ¿texto o espectáculo vivo? (editado por primera vez en 2007). Sus observaciones resultan complementarias a las de Zumthor.

Helbo establece dos subgrupos dentro de las llamadas "artes del espectáculo": las artes vivas y las mediáticas o mecanizadas. Las últimas se caracterizan por grabar y reproducir "un mismo mensaje estético en detrimento de su fuerza de acontecimiento" (Helbo, 2012, p. 43), mientras las "artes del espectáculo vivo" aplican un criterio inverso, ya que abarcan un conjunto de prácticas espectaculares guiadas por una intención estética "organizadas en función de las condiciones de enunciación ligadas a su naturaleza como evento" (Helbo, 2012, p. 43) único e irrepetible. La narración oral se encontraría dentro de este grupo, como una subcategoría, junto con el teatro, la ópera, el circo, el mimo, la danza, la danza-teatro, las artes callejeras, el festival, el espectáculo de marionetas, la corrida, las artes de feria y los conciertos, entre otros.

Complejidad y dinamismo, evanescencia e interdisciplina se sostienen a lo largo de los siglos y llegan al presente con el desafío de adaptarse

\footnotetext{
${ }^{5}$ Si bien el concepto figura en su libro La poesía y la voz en la civilización medieval (publicado por primera vez en 1984), este "aspecto corporal" (Zumthor, 2006, p. 12) también puede observarse en cualquier texto perteneciente a una cultura oral, es decir, sin conocimiento de la escritura o cuyo modo de comunicación no radica principalmente en esta. Incluso en civilizaciones provistas de escritura, el autor advierte: "[...] cabe dudar que / [...] aun las civilizaciones más profundamente impregnadas de los modelos de la escritura no conserven en su seno un espacio de libertad para la voz, por mínimo que este sea" (Zumthor, 2006, p. 12-13). En este sentido, cabría considerar, en mayor o menor medida, la existencia de "sensorialidad" o "corporalidad" en el uso del lenguaje como un aspecto recuperable en textos pertenecientes a cualquier cultura, letrada o no.
} 
a la tecnologizada era de las pantallas. ¿Cuál es el rol de la narración oral en la actualidad? ¿En qué medida su pervivencia continúa siendo necesaria? El siguiente apartado se centra en esta cuestión.

\section{Importancia de la oralidad en la era de la postmodernidad}

Según la investigadora Analía Vélez de Villa en su artículo "La condición posmoderna en la narrativa española” (2002), la era postmoderna se halla signada, entre otras cosas, por el eclecticismo (la variedad), el fragmentarismo y un gran despliegue intertextual. Además, como apunta Morduchowicz, en Los adolescentes del siglo XXI. Los consumos culturales en un mundo de pantallas, el mundo se rige por el uso (y en ocasiones abuso) de los massmedia y la innovación tecnológica, marcada inicialmente por la televisión y poco después por el uso de las computadoras que son cada vez más desplazadas por los celulares, en un mundo interconectado por las múltiples opciones que brinda/impone Internet. La era de la imagen ha pasado a constituirse en una era multimedial, donde las prácticas orales parecerían no tener cabida.

No obstante, esta condición global de las comunicaciones, ha permitido el desarrollo acelerado de una "oralidad secundaria", dependiente de lo escrito, generadora de estudios comparativos entre el universo de la oralidad y la escritura. Para el lingüista Walter Ong, dichos estudios nacieron "apenas en la era electrónica, no antes" (Ong, 2011, p. 12).

Las consecuencias de la revolución tecnológica actual van más allá del surgimiento de las prácticas orales cotidianas: la capacidad de "fijación" de la escritura se pierde cada vez más, los massmedia han reemplazado en gran medida, como apunta Estela Zalba (2003) al lenguaje escrito (y al libro) tradicional por otro multimedial, complejo y de percepción simultánea. Asimismo, el uso de las nuevas tecnologías ha facilitado la grabación y reproducción de hechos artísticos, lo que ha favorecido una concepción de "consumo" en relación con el arte y una acelerada "masificación del público" (Helbo, 2012, p. 43).

Ana Padovani, en su libro Escenarios de la narración oral. Transmisión y prácticas (2014), reflexiona sobre estas circunstancias en relación con las prácticas orales artísticas, trayendo a su discurso las palabras de Walter Benjamin, de la siguiente manera:

¿En qué afectó este cambio de paradigma cultural la relación entre el hombre y el arte? Por empezar, y potenciando un fenómeno originado en la modernidad, los espacios de congregación social fueron suplidos vertiginosamente por lo que llamamos "tecnificación de la información". Como ya explicaba Walter Benjamin, la obra de arte, susceptible a ser replicada, pierde su "aquí y ahora" con el avance de la reproducción técnica, "esa devaluación la hiere en lo más íntimo, en un punto más vulnerable que el de cualquier objeto natural: en su autenticidad [...]" (Padovani, 2014, p. 56).

Tanto esta autora como Helbo postulan la reivindicación de las artes del espectáculo vivo en el contexto descripto. El semiólogo francés se centra en las representaciones teatrales (con características comunes en su mayoría a las performances orales): se trata de un arte imposible de ser reproducido, concebido para una recepción colectiva, constituida por espectadores activos que co-crean el mensaje y concluye:

Alk donde la imagen del consumo se da como terminada, totalitaria, la de la escena se ofrece como resistente, requiere la concentración y la confusión, y plantea la cuestión del acceso a lo real, de la diferencia, de la construcción semiótica (Helbo, 2012, p. 44). 
Padovani, por su parte, se centra en el fenómeno de la narración oral, de la cual afirma:

[...] escapa a la lógica de reproducción voraz. Su naturaleza, podríamos decir, tiene un carácter casi artesanal, es la de un 'aquí y ahora', y posee una cualidad de acontecimiento original, especial y único: nunca se narra dos veces de la misma manera (Padovani, 2014, p. 59).

Pero la lógica de "consumo" que las prácticas orales artísticas rebaten desde su naturaleza, se extiende también a otras áreas de la existencia. El ser humano promedio debe adquirir bienes a cambio de tiempo que traduce en dinero, con el cual compra objetos vendidos por las corporaciones. Estas roban su tiempo y aumentan su dinero, cerrando un círculo en el que ellas nunca "pierden”, mientras el ser humano se deshumaniza. ¿Cómo escapar a esta lógica? A través de actividades que nos conecten al individuo consigo mismo, con los demás y con saberes profundos que le recuerden quién es. Las prácticas orales adquieren, así, un valor ontológico en la defensa del ser humano en su más genuina expresión.

\section{Conclusiones}

A lo largo de estas páginas, se ha pretendido explicar la vigencia e importancia de las prácticas orales artísticas. Para ello, inicialmente se ha recurrido a la concepción de "arte como saber", como recurso para acceder a la "verdad" (en tanto desocultamiento del "ser"), a partir del insumo teórico de los filósofos fenomenológicos (Georg Wilhelm Friedrich Hegel, Martin Heidegger y Hans-Georg Gadamer), precursores de la corriente de estudios literarios denominada "Teoría de la recepción”, enfocada en el rol activo del destinatario del mensaje en la co-construcción de sentido.
En una segunda instancia, partiendo de una concepción de lenguaje como juego (Ludwig Wittgenstein), en el que cada individuo configura de manera compleja y dinámica el mundo en sus interacciones cotidianas (Pedro Reygadas Robles-Gil y Stuart Shanker), se definió el concepto de "performance" (Paul Zumthor). Esto permitió explicar el tratamiento especial que el performer hace de elementos verbales y no verbales en el uso artístico de la palabra oral.

Posteriormente, se hizo referencia a la narración oral como una de las "artes del espectáculo vivo" (André Helbo) y se reparó en su originalidad y evanescencia como herramientas de humanización en una era postmoderna, habitada por sociedades letradas que redescubren el valor de la oralidad en la actualidad (Walter Ong). En este punto, se reivindicó la tarea de los narradores orales que ejercen su labor en un mundo mecanizado donde se evidencia, en mayor o menor medida, la masificación del público y la reproducción en serie de experiencias estéticas.

A partir de lo observado, puede considerarse que las prácticas orales forman parte de aquel conjunto de actividades que conectan al ser humano consigo mismo y con su comunidad. Estas, cuyo origen se remonta a milenios de antigüedad, revisten un valor ontológico e histórico en la defensa del ser humano en su más genuina expresión, en tanto recurso humano para el autoconocimiento la asimilación y comprensión del universo cultural nos precede y nos rodea. 


\section{Referencias}

Benítez Schaefer, L. (2017). La oralidad: vigencia de un arte ancestral en la era de la postmodernidad. Actas de I Jornadas de Ciencia, Técnica y Posgrado de la Facultad de Filosofía y Letras. En formato CD. Mendoza: Ediunc.

Benítez Schaefer, L. (2017) Reflexiones en torno de los conceptos trabajados en "El Arte como Saber". Seminario dictado por el Dr. Oscar Santilli. (inédito)

Benítez Schaefer, L. (2017) En torno a una aplicación didáctica de la TSD: El tratamiento interdisciplinario del "Romance del Infante Arnaldos". (en prensa)

Gadamer, H. G. (1993). Verdad y método. Quinta edición. Salamanca: Ediciones Sígueme.

Heidegger, M. (1988). Arte y poesía. Primera edición. México: Fondo de Cultura Económica.

Helbo, A. (2012). El teatro: ¿texto o espectáculo vivo? Primera edición. Buenos Aires: Galerna.

Morduchowicz, R. (2013). Los adolescentes del siglo XXI. Los consumos culturales en un mundo de pantallas. Primera edición. Buenos Aires: Fondo de Cultura Económica.

Ong, W. J. (2011). Oralidad y escritura. Tecnologías de la palabra. Primera edición. Buenos Aires: Fondo de Cultura Económica.

Padovani, A. (2014) Escenarios de la narración oral. Transmisión y prácticas. Primera edición. Buenos Aires: Paidós.

Reygadas, P. y Shanker, S. (2007). El rizoma de la racionalidad: El sustrato emocional del lenguaje (col. Revolución del pensamiento). Primera edición. México: Cenzontle Grupo Editorial y Universidad Autónoma de San Luis de Potosí.
Vélez de Villa, A. (2002) La condición posmoderna en la narrativa española. Letras, 45, monográfico, siglo XX. Buenos Aires: UCA, FFyL (p. 63-76).

Wittgenstein, L. (1988) Investigaciones Filosóficas. Primera edición. Barcelona: Crítica (Filosofía, serie clásicos).

Zalba, E. M. (2003). La lectura como práctica social históricamente situada. En: Gómez de Erice, M. V. y Zalba, E. M. Comprensión de textos: Un modelo conceptual procedimental. Mendoza: EDIUNC.

Zumthor, P. (1991). Introducción a la poesía oral. Primera edición. Madrid: Taurus Humanidades.

Zumthor, P. (2006). La poesía y la voz en la civilización medieval. Primera edición. Madrid: Abada. 